\section{P-72 NOT HIDING WHO I AM. SUPPORTING LGBT+ STAFF IN HOSPICES}

Martin Powell. London Hospices LGBT Network, London, UK

\subsection{6/bmjspcare-2019-HUKNC.95}

Background In the United Kingdom there is increasing interest in how LGBT patients access and experience healthcare, including end of life and palliative care. We know there is higher prevalence of life-limiting disease in LGBT people, attributed to lifestyle factors and fear of homophobia, discrimination and marginalisation (Marie Curie, 2016).

Much less attention is paid to LGBT staff, and of interest to us those working in hospices, and their support needs. A quarter of LGBT health and social care staff report experiencing bullying, discrimination or other forms of poorer treatment due to their sexual orientation (Quaile, 2018). When staff are healthy and happy, absenteeism is reduced, the workforce is more efficient and most importantly, patients receive better care (NHS Employers, 2019).

Aim The London Hospices LGBT Network was launched in October 2017, following collaboration between nine hospices who marched at London Pride. The network aims to:

- Promote equality, diversity and inclusion of LGBT people across London hospices;

- Provide leadership, support and education;

- Raise awareness of hospice care in LGBT communities.

Methods All London hospices were invited to join the network. The Network launched with a learning event to share the findings from the acclaimed ACCESSCare project (Bristowe, Hodson, Wee, Almack, et al., 2018), and the Marie Curie survey of hospice staff, 2016. Quarterly network meetings established.

Results Eleven hospices are network members. Nine hospices will march at London Pride in 2019. Hospices in the Midlands and Bristol were inspired to march in their own regional Pride. Newsletter produced and sent to all London hospices. Training planned for November 2019 at Hospice UK.

Conclusion The London Hospices LGBT Network has raised the profile of the LGBT hospice workforce, encouraging visibility, engagement and offering support to those who may be isolated and at risk of marginalisation or discrimination in the workplace. The network believes that acknowledging the difference and contribution that LGBT staff make leads to better outcomes for everyone.

\section{P-73 PRINCIPLES OF LEAN MANAGEMENT AND FACILITATING STAFF ENGAGEMENT: 'GET ON' BOARD}

Ruth Frost, Sarah Bradfield, Gail Ewins. Garden House Hospice Care, Letchworth, UK

\subsection{6/bmjspcare-2019-HUKNC.96}

Background Recently clinical team leaders across all clinical services attended 'Lean' training in order to support cultural change within the organisation and focus on more efficient processes to eliminate waste and maximise customer value. This training included the use of information boards within departments.

Aim To utilise information boards to foster staff engagement, by supporting teams to understand how the work they are doing fits in with the organisational strategic objectives, and accountability for performance at all levels and to improve communication.

Method The information boards were set up to provide a powerful communication and problem-solving tool, with team information and performance physically displayed on boards. Sections include: celebrate success, highlight issues/irritations, ideas/inspirations and areas to improve.

The data section contains the metrics each team needs to judge how well it is doing and what needs to change to create improved performance relating directly to the team's contribution to the achievement of the Clinical Objectives. It is the team's responsibility to update the board.

It is NOT just a notice board.

Results The boards have been rolled out across all clinical departments and follow the same basic principles but are tailored to the team needs. The services/teams are more actively engaged with the clinical services strategic business plan and links organisational objectives and policies to implementation. Each information or 'Get on' Board is supported by monthly briefings to discuss performance, celebrate success, review and update.

Clinical team leaders are using the information 'Get On' Boards to guide their teams to problem areas. Feedback from teams indicate that the boards are improving team performance.

Conclusion These boards have encouraged whole team engagement with clinical services strategy/strategic business plan and staff values. Visual status is clear and is understood and owned by front line staff.

\section{P-74 HARNESSING LEADERSHIP POTENTIAL IN THE HOSPICE}

Jackie Stone, Nick Dey. St Columba's Hospice, Edinburgh, UK

\subsection{6/bmjspcare-2019-HUKNC.97}

Background As part of a strategic plan a hospice in Scotland invested in a Leadership and Management Development programme for clinical and non-clinical staff which was delivered over three years. This was based upon the principle that professionals require a combination of leadership and management skills in order to ensure the services they provide are of the highest quality and person-centred. We believe that leadership and management skills are required at all levels in the hospice to ensure that each department and/or team continuously works to achieve the strategic and operational objectives of the hospice. In essence leadership skills are not just for those at a very senior level.

Aims

- To develop leadership and management skills within the hospice to support and ensure that each department and/or team continuously works to achieve the strategic and operational objectives of the hospice;

- To enable true staff engagement with implementation of the hospice's strategic objectives.

Method Three programmes were delivered over three years with each programme lasting for twelve months and thirty staff members participating in total. The underpinning philosophy of the programme is based on person-centeredness with each individual bringing their own unique set of skills and previous experiences into the programme. The programme consisted of a number of different elements: workshops, 
action learning sets, 360 degree feedback on their leadership behaviours and the opportunity to lead on a specific service or practice development project relevant to their role.

Results Evaluation demonstrated that participants developed their abilities in:

- self-awareness, self-management and personal development;

- developing and enhancing person-centred services and care;

- managing effective relationships with team members within the hospice;

- networking and partnership working.

In addition participants designed and led a quality improvement project specific to their own area of work which supported the implementation of the hospice strategy.

\section{P-75 IMPROVED MANAGEMENT PRACTICE THROUGH A FOCUSED DEVELOPMENT PROGRAMME}

Elizabeth Pattison. Peace Hospice Care, Watford, UK

\subsection{6/bmjspcare-2019-HUKNC.98}

Background In 2016 we introduced a Management Development Programme for senior managers. Programme evaluation highlighted benefits: managers bonded, gained a sense of collective responsibility, felt more confident in their roles and improved their communication within teams. Consequently, the programme was repeated for next level of management.

Aims To evaluate this second programme using the Kirkpatrick Model (Evaluating training programs, 1994), focusing on impact of managers' behaviours in relation to implementation of policies and performance management.

Method After modules attendees completed an evaluation/feedback questionnaire that measured reaction (level 1 evaluation) and learning (level 2 evaluation). Changes in behaviour (level 3 evaluation) were undertaken through individual interviews and group reflection session.

Results Initial reactions of attendees (Level 1):

- $99.5 \%$ agreed course was relevant to them;

- $96.5 \%$ agreed quality of training was high;

- $95.5 \%$ agreed session(s) would be useful in their work.

Learning (level 2) was evaluated through the question 'How do you hope to change your practice as a result of this training?' This question was answered $57 \%$ of the time and answers included: improvement in communication, confidence, management style. Some $18 \%$ of those who answered said they needed to reflect.

Examples given of subsequent changes in management behaviour (level 3 evaluation) included: increased confidence and assertiveness in performance management and management styles, more proactive sickness absence management, improved job descriptions and interview questions resulting in recruitment of higher calibre employees.

Quantitative longer-term results (level 4 evaluation) have yet to be established. Financial savings have been made through the proper management of long-term sickness absence.

Conclusion Evaluation of results (level 4) of this programme is ongoing through sickness absence, exit questionnaire, staff survey, performance management and appraisal monitoring. We plan to extend the programme in $2020 / 21$.

\section{P-76 DEVELOPING AND IMPLEMENTING A LEADERSHIP PROGRAMME FOR HOSPICE COMMUNITY NURSES}

Toni Flanagan, Helen Reeves, Katie Taroni. St Giles Hospice, Lichfield, UK

10.1136/bmjspcare-2019-HUKNC.99

Background and aims The aim of this project was to introduce an innovative leadership programme aimed at hospice nurses within the community palliative care team to help enhance their leadership skills and build resilience to reduce the risk of burnout. The programme aimed to develop nursing leadership skills, to enhance patient care and to improve practitioner self-management. To ensure the programme reflects the needs of the individuals and the group as a whole, a range of teaching and learning methods were employed. The programme included Myers Briggs Type Indicator (MBTI), FIERCE training, training on self-management techniques and change, group coaching and a workbook which supported the programme with self-reflection exercises. The programme was underpinned by the Clinical Leadership Competency Framework (NHS Leadership Academy, 2011) to ensure optimisation of leadership potential.

Method Focus groups were used to gather information from the participants regarding their understanding of leadership and how they felt about themselves as leaders.

Results Prior to the programme participants felt that the traits of a leader and the relationship between leader and follower were of paramount importance. There was also an acknowledgement from the participants that they did not self-identify as leaders in their role. Following the leadership programme further focus groups were used to evaluate the programme. Participants felt they had increased their confidence around their leadership skills and the programme had helped them to understand themselves and others more which they felt led to better team working which consequently increased resilience. Questionnaires were also used to demonstrate change in individuals with most showing an improvement in their confidence, self-management and team working.

Conclusion Overall, the evaluation of the leadership programme was extremely positive with the only suggested improvement to shorten the one-year programme to intensify the experience.

\section{P-77 RESTORATIVE PRACTICE: EMOTIONAL INTELLIGENCE IN THE WORKPLACE}

Ann Smith, Lesley Spencer. Princess Alice Hospice, Esher, UK

10.1136/bmjspcare-2019-HUKNC.100

Background/context In recent years evidence suggests that a happier workforce improves productivity and the quality of care being delivered to its service users. Restorative practice is an alternative, yet effective response to improving performance and avoiding unnecessary grievances. This approach saves time and the anxiety that can occur when there is conflict and unhappiness in the workplace. Restorative practice helps people to find their own solutions to problems and focuses more on the person rather than procedure.

Aim In 2016, the clinical department at Princess Alice Hospice began to adopt a less procedural approach to managing staff, and saw as a result the number of grievances fall with a happier workforce that played to the strengths of individuals. In 